Ageing E Society 33, 2013, 1053-1076. (C) Cambridge University Press 2012

The online version of this article is published within an Open Access environment subject to the conditions of the Creative Commons Attribution-NonCommercial-ShareAlike licence < http://creativecommons.org/licenses/by-nc-sa/2.5/>. The written permission of Cambridge University Press must be obtained for commercial re-use.

doi:10.1017/So144686X1200044X

\title{
A longitudinal analysis of the impact of family support on the morale of older parents in Japan: does the parent's normative belief in filial responsibilities make a difference?
}

\author{
EMIKO TAKAGI* and YASUHIKO SAITO ${ }^{\dagger}$
}

\begin{abstract}
Japan presents a unique social laboratory in which to examine how family support impacts on older adults' psychological wellbeing. This is because of its cultural climate where distinctively different expectations of old-age independence and the traditional norm of filial piety coexist. This study investigated how structural and functional dimensions of the family support of older Japanese parents influence their psychological morale, and whether the impacts of family support on parents' morale vary depending on the parents' belief in the traditional cultural norm of filial piety. Four waves of data from the Nihon University Japanese Longitudinal Study of Aging (NUJLSOA) collected in 1999, 2001, 2003 and 2006 were analysed. Combining the two- or three-year span of longitudinal data between each wave $(\mathrm{N}=3,882)$, an ordered logistic regression analysis was undertaken. The results reveal that although parents who were widowed or received emotional support from a child tended to report a lower level of morale, the negative influences of such support tended to be mitigated if the parent agreed with the traditional cultural norm of filial responsibilities. These results imply that the meaning and benefit of family support may differ depending on the degree to which Japanese older parents support the traditional norm of filial responsibilities.
\end{abstract}

KEY WORDS - social support, family, psychological wellbeing, filial piety, Japan.

\section{Introduction}

Previous studies have shown that the exchange of social support exerts a significant influence on older parents' psychological wellbeing in Western societies (e.g. Davey and Eggebean 1998; Silverstein, Chen and Heller 1996;

* Department of Health Science, Towson University, Towson, Maryland, USA.

$\dagger$ Advanced Research Institute for the Sciences and Humanities, Nihon University, Tokyo, Japan. 
Thomas 2010). These studies have been extended to different national and cultural contexts, particularly in East Asian societies that are under the influence of a traditional family norm of filial piety, such as China (e.g. Chen and Silverstein 2000; Cong and Silverstein 2008; Li, Song and Feldman 2009; Phillips et al. 2008) and Korea (e.g. Kim and Kim 2003; Kim et al. 2000). These studies are often discussed in contrast to the individualism prevalent in Western societies.

Japan is an interesting cultural context to explore issues related to family support for older adults because it is a highly developed and rapidly ageing country with a culturally unique environment where the traditional norm of filial piety coexists with an emerging social norm of independence in old age (Kumagai 1996). Several decades ago, Japan could have been described as a highly developed country that maintained a traditional family support system in which older parents expected to be fully cared for by their adult children (Palmore 1975). Since then, however, the country has gone through significant demographic and cultural changes that have resulted in a heightened need for public service intervention in order to support the rapidly growing older population (Muramatsu and Akiyama 2011). Studies have indicated that most of the needed support of older adults tends to be first delegated to their spouses (e.g. Cantor 1979). In this context, support from adult children has become more contingent upon needs of older parents such as their failing health and loss of a spouse (Brown et al. 2002; Takagi and Silverstein 2011). When compared to other East Asian societies that adhere to the norm of filial piety, Japan represents arguably one of the most advanced ageing societies in Asia because a deep cultural division has occurred and moved the country further away from the traditional norm of filial piety.

\section{Family support and the norm of filial piety in current Japanese society}

Many Asian societies, including Japan, have historically expected adult children to serve as primary care-givers for older parents. A principal underlying idea of filial piety is reciprocity in exchange for support. As such, adult children (especially the oldest son and his family) are expected to provide their parents with care and support as repayment for the sacrifices and efforts the parents had previously made for the child (Koyano 1996). In other words, the norm of filial piety allows older parents to be dependent on their children in old age as a cultural and social entitlement contract with their children. As a result, a lack of support from children may influence a parent's psychological wellbeing, as it may be perceived as a failure to obtain what they were entitled to receive from children in their later years. In fact, some studies in China have shown that receiving support 
from children in the form of financial assistance and co-residence tends to enhance a parent's psychological wellbeing (Chen and Silverstein 2000; Silverstein, Cong and Li 2006).

Recent studies on family relations in Japan have also shown that the force of the traditional family norm of filial piety on older adults' expectation for intergenerational family support is steadily dwindling, as is the actual occurrence of family support (Ogawa et al. 2007). For example, intergenerational co-residence between older parents and adult children has been subject to a continuous decline. Recent statistics suggest that the rate of co-residence among adults $6_{5}$ years and older in Japan has hit an historical low of 43 per cent, representing a continuous decline from almost 8o per cent in the 1950s (Cabinet Office 2011). Although the rate of co-residence is still relatively high compared to other similarly developed nations (Maeda and Ishikawa 200o), the historical trend clearly shows that the traditional family norm in Japan is steadily in decline.

Older parents in Japan also seem to have mixed feelings about relying on their children for support. For instance, Ogawa et al. (2007) reported that growing numbers of older adults in Japan express their preference not to rely on their children later in life. The repeated cross-sectional survey presented by Ogawa et al. (2007) shows that the proportion of older adults who plan not to rely on children doubled from 45 per cent in the 1960 s to nearly 90 per cent in 2006 (Ogawa et al. 2007). This, combined with the continuous decline of the actual practice of filial piety (e.g. coresidence), suggests that while Japanese families are aware of the traditional family norm, the act of receiving support from children that was once expected in one's later years in Japan now may be perceived as interference with desired independence. Subsequently, receiving support from children potentially has a negative influence on an older parent's psychological wellbeing.

With the practice of, and expectation for, filial support being in decline, social support provided by spouses arguably plays an even more crucial role for the wellbeing of older adults. Similar to what has been discussed in Western societies, a number of studies in Japan have depicted spouses, if alive and available, as a primary source of social support (Koyano 1994). At the same time, this implies that the lack of a living spouse presents a unique family condition for older adults, where the availability of support from adult children may become especially critical. In fact, widowhood has been identified as a major determinant of the likelihood of older parents' coresidence with adult children, suggesting that provision of intergenerational support may be contingent upon the availability of an older parent's spouse (e.g. Takagi and Silverstein 2011). 


\section{Social support and older parents' psychological wellbeing}

\section{Structural and functional aspects of social support}

Social support provided by family members has two major dimensions: structural and functional support (Chen and Silverstein 200o; Silverstein and Bengtson 1997). The structural aspect of social support consists of one's social network and its availability to provide support (Antonucci and Akiyama 1996). Generally speaking, the structural aspect of family support that is critical for current Japanese older adults' psychological wellbeing is represented by two components; one is the availability of a living spouse (i.e. widowhood), and the other is the availability of children who are expected to provide support to older parents. Although it is arguable whether spouses and children fulfil different roles in providing support, or are hierarchically situated in terms of their importance (Penning 1990), an older parent's widowed status creates a unique family dynamic where children tend to play a significant role. Widowhood itself has been examined extensively in relation to a surviving spouse's physical and psychological wellbeing. These studies generally suggest that widowhood tends to lead to negative psychological and physical circumstances for a surviving spouse (e.g. Elwert and Christakis 2006; Lee and DeMaris 2007; Umberson, Wortman and Kessler $1992)$.

The availability of children as a potential source of social support is assessed by the number of children a parent has, with a larger number of children suggesting a larger pool of resources of social support (e.g. Eggebeen 1992). Another measure of the structural component of intergenerational social support is the geographical proximity between children and parents. The closest proximity is intergenerational coresidence, where parents and children live together. Intergenerational coresidence is a particularly unique condition for exchange of support (Hayashi 1995; Pezzin and Schone 1997); and a co-residing child and child-in-law tend to play a critical role in providing and receiving support from older parents (Koyano 1994). On the other hand, living close but not together is increasingly preferred in Japan as an alternative to the traditional arrangement of co-residence (Tsuya and Martin 1992). Since the child living nearby could assure parents that support is readily available, having close proximity with at least one child may enhance parents' psychological wellbeing. Additionally, because of the patriarchal nature of the traditional family norm of filial piety, having at least one son may provide parents with a sense of security that they have a child who will assume a primary role of care provider. The study on intergenerational social support in China by Chen and Silverstein (2000), however, did not 
find the presence of a son in a family to be a significant determinant of parents' psychological wellbeing.

Another important dimension of social support is its functionality. The three major functions of social support considered in this study were financial support, instrumental support and emotional support. Financial support is monetary assistance. Examination of financial support as a unique aspect of social support is relatively limited, but because it requires financial resources and power, we considered it as a distinct function of social support. Instrumental support includes practical help for those in need, such as household chores, shopping and transportation. Emotional support, on the other hand, represents intangible support such as spending time together and listening to concerns.

The functionality of social support needs to be examined by looking at the help and assistance received and provided by older parents. Although support provided by older adults tends to receive limited attention, studies in the United States of America (USA) generally report that providing support to children tends to enhance the psychological wellbeing of older adults (e.g. Silverstein, Chen and Heller 1996; Thomas 2010). This tendency was also observed in other nations that embrace the norm of filial piety and accept parents' dependency on children in later years, suggesting that the act of providing support to children is important in order to fulfil the underlying norm of reciprocity (Kim et al. 2000).

In addition, the functionality of social support needs to be carefully examined by considering the quantity of support received or provided. Although measuring support in quantitative terms presents challenges, in general, research has suggested that either providing or receiving excessive amounts of support tends to negatively influence psychological wellbeing of older individuals (Silverstein, Chen and Heller 1996; Thomas 2010).

\section{Normative expectation for social support}

The ways in which patterns of family support influence older parents' psychological wellbeing is likely to differ depending on the parents' normative expectation for such support. Normative expectations for family support represent what parents consider ideal ways of assisting one another, and it represents one of the important dimensions of family relations (Roberts, Richards and Bengtson 1991). Some of the past studies in the USA (e.g. Lee, Netzer and Coward 1995) have suggested that parents with a relatively high expectation of filial support are more likely to suffer from decreased psychological wellbeing. Lee, Netzer and Coward (1995), 
for example, discussed in Western societies at least, an older adult's positive attitude toward filial expectations may be an indication of his or her struggle to achieve independence in old age.

The relationship between a Japanese parent's filial expectation and his or her psychological wellbeing may be different from what is found in the USA, as the Japanese cultural norm of filial piety tends to allow older parents to be dependent on children. For instance, the study by Cheng and Chan (2006) with older Chinese parents showed that, in contrast to results from studies in Western societies (e.g. Davey and Eggebean 1998; Öztop et al. 2oog; Silverstein et al. 1996), receiving support from children did not exert a negative influence on a parent's psychological wellbeing. Their study also highlighted the importance of parents' sense of respect from their children, which played a crucial role in maintaining parents' psychological wellbeing. Given the significant cultural shift that has already occurred in Japanese society, it is yet to be seen how a parent's normative belief plays a role in shaping the psychological wellbeing of Japanese older parents.

Findings that discuss older parents' belief in children's filial responsibilities as a significant determinant of psychological wellbeing (e.g. Cheng and Chan 2006) lead us to expect that the ways in which structural and functional family support impact older parents' psychological wellbeing in Japan may also be mitigated by the parent's attitudes toward the traditional family norm. For instance, given the presumably heightened need of support from children after the loss of a spouse, the psychological damage caused by widowhood may be better resisted if older parents hold a relatively strong belief in children's filial responsibilities compared to parents who have less faith in such filial duties. Similarly, receipt or provision of support to children may be perceived and influence differently depending on parents' attitudes toward filial responsibilities.

Although the nature of family support and its potential influences on an older parent's wellbeing has been extensively explored, the results and findings to date are rather inconsistent. This is partly due to the fact that, overall, research is mostly limited to cross-sectional studies (see exceptions in Davey and Eggebean 1998; Li, Song and Feldman 20o9). Although well-designed cross-sectional studies are capable of deciphering mechanisms in which different dimensions of social support influence older parents' psychological states, empirical proof of its cause is not strongly present. Furthermore, there needs to be more research on this topic in a variety of cultural contexts in order to enhance our understanding of the ways in which cultural beliefs and expectation may shape the influence of social support on older adults' psychological wellbeing. 


\section{Study purpose}

The purpose of this study was to investigate how the availability and patterns of family support are associated with the psychological wellbeing of Japanese older parents who have varying degrees of belief in the traditional norm of filial piety. We used data from a nationally representative sample of the older population in Japan that pooled three sets of two- or three-year longitudinal data collected between 1999 and 2006. Japan provides an interesting environment to explore this topic because of its substantial within-cohort variability in the extent to which the traditional family norm of filial practice is supported and practised.

We hypothesised that, given the growing preference among older Japanese adults for staying independent from children as they age, the influence of family support on their psychological wellbeing would be aligned with what we have observed in societies such as the USA that have individualistic norms. In this context, we contend that a desire for independence from children in one's later years makes the presence of a spouse particularly important. We therefore expected that widowhood has a negative influence on an older parent's psychological wellbeing. We also expected that parents' desire to stay independent in general would make the act of receiving social support from children negatively related to their psychological wellbeing. Furthermore, we hypothesised that providing support to children is important for older parents to maintain their psychological wellbeing, as a way of fulfilling the norm of reciprocity. We also proposed that the impact of the presence or absence of various dimensions of family support on older parents in Japan differs depending on the extent to which they embrace the traditional norm of filial piety. More specifically, we expected that relatively 'traditional' parents may be better able to maintain their psychological wellbeing in widowhood because of their belief that children should provide care in a parent's later life. At the same time, we hypothesised that for parents with more 'traditional' attitudes, receiving support from children may be perceived as acceptable or desirable and therefore does not negatively influence their psychological state.

\section{Methods}

\section{Data and sample}

We analysed data from the Nihon University Japanese Longitudinal Study of Aging (NUJLSOA), which was conducted in four waves: 1999, 2001, 2003 and 2006. The NUJLSOA is a national longitudinal study that focuses on the 
health and social conditions of the Japanese population aged $6_{5}$ years and older (USC/UCLA Center on Biodemography and Population Health 2004). The survey began in 1999 with a baseline sample of 4,997 respondents (response rate: $74.6 \%$ ). The study over-sampled those 75 years and older for a close analysis of the relatively older segment of the population. The survey contains longitudinal data on participants who survived and returned to the study at four different points in time: in 1999, 2001, 2003 and 2006. In 2001 and 2003, the study added new participants aged $6_{5}$ and 66, respectively. This study included participants who were tracked longitudinally since the first wave in 1999 as well as those who were newly added in 2001 and 2003.

Our analysis was based on self-reporting data from community-dwelling older adults who had at least one living adult child and who participated in at least two consecutive waves of the study $(\mathrm{N}=4,226)$. Our study sample was further restricted to those who completed all questions, except for the question on household income, which had a relatively large proportion of omissions (about 21 per cent of the study sample). The income for nonresponders was imputed using a hotdeck method, which replaced missing values based on key demographic values (i.e. age, gender and education) of other cases with no missing value. All other variables did not have more than a 5 per cent non-response rate.

Data were constructed to observe a change between each of the four waves, yielding three study intervals: from wave one to wave two (19992001), wave two to wave three (2001-2003), and from wave three to wave four (2003-2006). For each interval, selected variables were measured either at the beginning or at the end of the interval, or both. Ultimately, data from each of the three intervals were pooled and analysed, which included two- or three-year-long longitudinal observations $(\mathrm{N}=3,882)$ provided by 2,380 individuals. Among those 2,380 study participants, 1,080 older adults were present in multiple study intervals (providing 2,582 observations) and 1,300 older adults participated in only one of the three study intervals. Because the interval between the third and fourth wave was three years whereas the other waves had two years in between, a variable to indicate data belonging to the three-year interval was included as a control. We used weight variables that were developed for each study interval throughout our analysis. Sampling weights at the baseline survey were computed for representativeness of the sample accounting for oversampling of those aged 75 and over. For each follow-up survey, new sampling weights were computed for representativeness of the sample accounting for the probability of loss to follow-up. We have three interval observations at most for a sample person, and we applied weights at the beginning of the interval for statistical analyses. 


\section{Dependent variable: psychological wellbeing}

The outcome variable of older parents' subjective wellbeing was assessed with the 1 1-item version of the Philadelphia Geriatric Center (PGC) Morale Scale (Lawton 1975; Liang et al. 1987). We used the data collected at the end of each study interval as an outcome variable. Our analysis also included the morale score assessed at the beginning of the interval as a control. In the survey, each item of the PGC Morale Scale was assessed with two response categories $(1=$ yes, $\mathrm{O}=\mathrm{no})$. We reversed coding of several questions for our total score calculation, and scored each item as either o (=answered as 'no') or 1 (=answered as 'yes'). The total resulting score ranged from o (lowest morale) to 11 (highest morale).

Our preliminary analysis showed that the internal consistency of this scale was fairly high $(\alpha=0.75$ at baseline and $\alpha=0.74$ in the end of the study interval). Because the distribution of the total score was skewed to the highest score $($ mean $=8.6$, standard deviation $(\mathrm{SD})=2.3$ measured at the end of the study interval), we converted the outcome variable of the PGC morale score to a three-level ordered variable that ranged from 1 ('low morale') to

3 ('high morale'), with each level including approximately one-third of the sample. The PGC morale score measured at the baseline of the study interval was also similarly skewed (mean $=8.7, \mathrm{SD}=2.2$ ). Because the baseline score was used as a predicting variable rather than an outcome variable, we used it in its original form in our analysis.

\section{Structural and functional support measurements}

Structural aspects of social support were assessed with older parents' family characteristics and living arrangements. The presence of a living spouse was represented as marital status ( $1=$ widowed, $\mathrm{O}=$ other status). Regarding support availability from children, we included variables for the number of children, presence of a son ( $1=$ yes, $\mathrm{O}=$ otherwise), co-residence with a child ( 1 = lives with a child, $\mathrm{O}=$ does not live with a child) and the presence of a noncoresident child living in the same city. Time-variant structural support variables of widowhood, co-residence and non-coresident child in the same city were measured at the beginning and at the end of each study interval and both data were included in our analysis.

For the measurement of functional support, information about social support between older parents and children was retrieved from responses from older participants with up to ten biological or adopted children. In the survey, participants were asked whether they received any support (not limited to financial support) from each child they reported to have. For those parents who answered 'yes', the subsequent question asked about the types of support they received from each child, listing eight types 
of support: financial, help with food/meals, help with housework such as laundry and cleaning, transportation/getting around, companionship, shopping and errands, consultation/advice for troubles, and other. The parents were also asked about the support they provided to each child, with the selection of the same eight types of support as well as the additional item of caring for grandchildren.

Using these questions, we created three categories of support: financial support, instrumental support (i.e. help with food/meals, housework, transportation, shopping) and emotional support (i.e. companionship and consultation). Next, we aggregated information relating to help and support to and from the multiple adult children that each older parent reported, and created six sets of dummy variables. Three of these variables represented parents' receipt of support from children (i.e. $1=$ received financial/instrumental/emotional support from at least one of the children, $\mathrm{o}=$ otherwise); and the other three indicated parents' provision of support to the children (i.e. 1 =provided financial/instrumental/ emotional support to at least one child, $\mathrm{o}=$ otherwise). The exchange of support was measured at the beginning and at the end of the study interval, and both sets of variables were included in the subsequent analyses. Additionally, using the types of support provided in the survey, the quantitative aspect of family support function was assessed based on the number of support items older parents reported that they had either received or provided.

\section{Socio-demographic characteristics}

The socio-demographic characteristics of the older adults captured in this study included age (in years), gender $(1=$ female, $\mathrm{o}=$ male) and rural residency $(1=$ lives in a rural area, $\mathrm{o}=$ lives in an urban area). Educational achievement was assessed using a dummy variable indicating whether the individual had a high school or higher education. Household income was assessed with a 13-point scale (ranging from $1=$ less than 5 oo, ooo Japanese yen (approximately US $\$ 6,25^{\circ}$ ) to $13=$ more than 15 million Japanese yen (approximately US $\$ 187,500$ )).

We considered the health status of older adults as a significant indicator of their psychological state, as well as of their need of support from others. We used the older adults' self-report regarding his or her ability to conduct the activities of daily living (ADLs) in seven areas: taking a bath/shower, dressing, eating, standing up from a bed or a chair, walking (around house), going outside (leaving home), and going to bathroom/using toilet. These $\mathrm{ADL}$ items were measured on a four-point scale from 1 (not difficult) to 4 (unable to perform). Due to skewed distribution, we combined individual 
items for ADL, and created a dichotomous variable indicating whether the individual had difficulty performing at least one ADL item (=1) or no difficulty in any of the seven ADL items $(=0)$.

Older parents' attitudes toward filial care responsibilities were measured by the participants' agreement with the following statement: 'A child should be expected to support and take care of his or her aged parents, as the child should feel a sense of gratitude to the parents for raising him/her.' Responses ranged from disagree (1) to agree (4). With this scale, we considered parents with higher scores to have a relatively more 'traditional' view toward intergenerational family support and arrangements.

\section{Statistical model}

With the three-level morale scale as an outcome variable, ranging from 1 ('low morale') to 3 ('high morale'), we implemented a set of ordered logistic regression analyses. First, we ran a baseline model where we only included main control effects. Next, we added variables related to structural and functional family support measured both at the initial and at the end of each study interval to examine their influence on a parent's morale score. Finally, we examined if a parent's attitudes toward the traditional family norm moderates the effects of structural and functional social support by including a series of interaction terms between the parent's normative attitudes and the 12 structural and functional family support variables included in our previous model.

\section{Results}

Table 1 shows the characteristics of our sample of older parents (all numbers presented in the table are weighted values). Their average age was 72 years. Slightly more than half $(54 \%)$ were women. About one-third (33\%) resided in rural areas. Respondents had an average household income between 2 million Japanese yen (about US \$25,0oo) and 4 million Japanese yen (about US $\$ 5$ o,ooo). Slightly less than half ( $47 \%$ ) of the older parents in our sample had at least a high school education. At the beginning of the study interval, about 5 per cent of the sample had at least one ADL disability. That number increased slightly to 7 per cent at the end of the study interval. More than half of the sample $(59 \%)$ either agreed or somewhat agreed with the given statement regarding the traditional family norm of filial obligation at the beginning of the study interval.

Table 2 presents data related to the structural and functional dimensions of family support. Regarding the structural measure of family support, 
TA в LE 1. Sample characteristics

\begin{tabular}{lcc}
\hline Variables & Range/categories & $\begin{array}{c}\text { Mean }(\mathrm{SD}) / \\
\text { Proportion }\end{array}$ \\
\hline PGC morale score (baseline) & $1-11$ & $8.7(2.2)$ \\
PGC morale score (ending year) & 1 (low morale) & 0.27 \\
& 2 (middle morale) & 0.29 \\
Age & 3 (high morale) & 0.44 \\
Gender (female) & $65^{-94}$ & $72.4(5.6)$ \\
Rural residency & Female $=1$, male $=0$ & $0.54(0.50)$ \\
Household income (imputed) & Yes $=1$, no $=0$ & $0.33(0.47)$ \\
& 1 (less than US $\$ 6,250)$ to 13 & $5.2(2.3)$ \\
High school or higher & (more than US $\$ 187,500)$ & \\
ADL difficulty (baseline) & Yes $=1$, no $=0$ & $0.47(0.50)$ \\
ADL difficulty (ending year) & Yes $=1$, no $=0$ & $0.05(0.22)$ \\
Filial responsibility & Yes $=1$, no $=0$ & $0.07(0.26)$ \\
& Disagree & 0.25 \\
& Somewhat disagree & 0.16 \\
& Somewhat agree & 0.23 \\
& Agree & $0.3^{6}$
\end{tabular}

Notes: $\mathrm{N}=2,380$ (observations = 3,882). ADL: activity of daily living. PGC: Philadelphia Geriatric Center. SD: standard deviation.

slightly more than one-quarter $(27 \%)$ did not have a living spouse (i.e. widowed) initially; and the prevalence increased slightly by the end of the study intervals $(30 \%)$. Respondents had an average of 2.4 children, and slightly more than half $\left(5^{2-53 \%)}\right.$ of the sample reported that they lived with their child at both the beginning and the end of the study intervals. At both ends of the study intervals, less than half $\left(45^{-46 \%}\right)$ of the parents had at least one child residing in the same town. A majority of the parents $(80 \%)$ reported that they had at least one son.

Regarding the three types of support that make up the functional aspect of social support, receiving and providing financial support occurred relatively less frequently ( $16-20 \%)$. A similar proportion of parents provided and received instrumental support from their children (23-25\%). A larger proportion of older adults $\left(25^{-26 \%}\right)$ reported they received emotional support, whereas a much smaller portion provided such support to their children $(14 \%)$.

An analysis of the three models we tested is presented in Table 3. In all three models, parents' relatively high educational level (i.e. high school or beyond) and presence of an ADL disability (with the inclusion of baseline ADL measure as a control) appeared to be significantly associated with their morale. Specifically, the proportional odds ratios (POR) suggest that completion of high school or a higher level of education increased the likelihood that an individual would report a one level higher morale 
T A B LE 2. Social support

\begin{tabular}{|c|c|c|}
\hline Variables & Range/categories & $\begin{array}{c}\text { Mean }(\mathrm{SD}) / \\
\text { Proportion }\end{array}$ \\
\hline \multicolumn{3}{|l|}{ Structural social support: } \\
\hline Widowhood (baseline) & $\begin{array}{l}\text { Widowed }=1, \text { not } \\
\text { widowed }=0\end{array}$ & $0.27(0.45)$ \\
\hline Widowhood (ending year) & $\begin{array}{l}\text { Widowed }=1, \text { not } \\
\text { widowed }=0\end{array}$ & $0.3^{\circ}\left(0.4^{6}\right)$ \\
\hline Co-residence with adult child (baseline) & Yes $=1$, no $=0$ & $0.53\left(0.5^{0}\right)$ \\
\hline Co-residence with adult child (ending year) & Yes $=1$, no $=0$ & $0.5^{2}\left(0.5^{0}\right)$ \\
\hline $\begin{array}{l}\text { Non-coresident child living in the same } \\
\text { town (baseline) }\end{array}$ & Yes $=1$, no $=0$ & $0.45\left(0.5^{0}\right)$ \\
\hline $\begin{array}{l}\text { Non-coresident child living in the same } \\
\text { town (ending year) }\end{array}$ & Yes $=1$, no $=0$ & $0.4^{6}\left(0.5^{0}\right)$ \\
\hline Number of children & $1-8$ & $2.4(0.96)$ \\
\hline Having at least one son & Yes $=1$, no $=0$ & $0.80(0.40)$ \\
\hline \multicolumn{3}{|l|}{ Functional social support: } \\
\hline \multicolumn{3}{|l|}{ Receiving support: } \\
\hline Financial support (baseline) & Yes $=1$, no $=0$ & $0.16(0.39)$ \\
\hline Financial support (ending year) & Yes $=1$, no $=0$ & $0.17(0.37)$ \\
\hline Instrumental support (baseline) & Yes $=1$, no $=0$ & $0.19(0.40)$ \\
\hline Instrumental support (ending year) & Yes $=1$, no $=0$ & $0.23(0.42)$ \\
\hline Emotional support (baseline) & Yes $=1$, no $=0$ & $0.23(0.42)$ \\
\hline Emotional support (ending year) & Yes $=1$, no $=0$ & $0.25(0.43)$ \\
\hline Number of support (baseline) & $1-7$ & $0.87(1.5)$ \\
\hline Number of support (ending year) & $1-7$ & $0.97(1.6)$ \\
\hline \multicolumn{3}{|l|}{ Providing support: } \\
\hline Financial support (baseline) & Yes $=1$, no $=0$ & $0.18\left(0.3^{8}\right)$ \\
\hline Financial support (ending year) & Yes $=1$, no $=0$ & $0.18\left(0.3^{8}\right)$ \\
\hline Instrumental support (baseline) & Yes $=1$, no $=0$ & $0.26(0.44)$ \\
\hline Instrumental support (ending year) & Yes $=1$, no $=0$ & $0.25(0.43)$ \\
\hline Emotional support (baseline) & Yes $=1$, no $=0$ & $0.14(0.35)$ \\
\hline Emotional support (ending year) & Yes $=1$, no $=0$ & $0.13(0.34)$ \\
\hline Number of support (baseline) & $1-8$ & $0.94(1.5)$ \\
\hline Number of support (ending year) & $1-8$ & $0.86(1.5)$ \\
\hline
\end{tabular}

Notes: $\mathrm{N}=2,389$ (observations $=3,882$ ). SD: standard deviation.

by about 27 per cent. On the other hand, if the parent had an ADL disability, it is 6o per cent more likely that that individual reported one level lower in morale score. The relatively high level of morale score at the initial time of the study interval suggested a baseline of one's overall higher morale, therefore their corresponding ending morale level also tended to be higher.

Although it did not reach the conventional statistical level of significance, one of the structural social support measures (i.e. end-of-interval widowhood status in the final model) was identified as a relatively important contributor to older parents' morale. With the control of the widowhood status in the initial time of the study interval, the lack of spousal support resulting from 
Ta b L 3. Ordered logistic regression

\begin{tabular}{|c|c|c|c|c|c|c|}
\hline \multirow[b]{2}{*}{ Predictors } & \multicolumn{2}{|c|}{ Model 1} & \multicolumn{2}{|c|}{ Model 2} & \multicolumn{2}{|c|}{ Model $_{3}$} \\
\hline & Coefficient & POR & Coefficient & POR & Coefficient & POR \\
\hline \multicolumn{7}{|l|}{ Parent's characteristics: } \\
\hline Age & -0.01 & $0.99^{*}$ & -0.01 & 0.99 & -0.01 & 0.99 \\
\hline Gender (=female) & -0.02 & 0.98 & 0.01 & 1.01 & o.oo & 1.00 \\
\hline Rural residency & -0.09 & 0.91 & -0.10 & 0.91 & -0.10 & 0.90 \\
\hline High school education or higher & 0.25 & $1.28 * *$ & 0.24 & $1.27^{* *}$ & 0.24 & $1.27^{* *}$ \\
\hline Household income & 0.01 & 1.01 & 0.01 & 1.01 & 0.01 & 1.01 \\
\hline Filial attitudes & -0.04 & 0.96 & -0.04 & 0.96 & -0.07 & 0.93 \\
\hline ADL difficulty (baseline) & -0.17 & 0.85 & -0.09 & 0.92 & -0.06 & 0.94 \\
\hline ADL difficulty (ending year) & -0.93 & $0.40^{* * *}$ & -0.91 & $0.40^{* * *}$ & -0.90 & $0.40^{* * * *}$ \\
\hline PGC morale baseline score & 0.40 & $1.49 * * *$ & 0.40 & $1.49^{* * * *}$ & 0.40 & $1.49 * * *$ \\
\hline Data belong to the three-year interval $(2003-06)$ & -0.38 & $0.69 * * *$ & -0.38 & $0.69 * * *$ & -0.38 & $0.69 * * *$ \\
\hline \multicolumn{7}{|l|}{ Structural social support: } \\
\hline Widowhood (baseline) & & & -0.09 & 0.91 & -0.10 & 0.90 \\
\hline Widowhood (ending year) & & & 0.02 & 1.02 & $-0.4^{6}$ & $0.63 \dagger$ \\
\hline Number of children & & & 0.05 & 1.05 & 0.05 & 1.05 \\
\hline Co-residence with a child (baseline) & & & -0.13 & 0.88 & -0.13 & 0.87 \\
\hline Co-residence with a child (ending year) & & & 0.27 & $1.31 \dagger$ & 0.39 & $1.4^{8}$ \\
\hline Children living in the same city (baseline) & & & 0.01 & 1.01 & 0.02 & 1.02 \\
\hline Children living in the same city (ending year) & & & -0.13 & 0.88 & -0.12 & 0.89 \\
\hline Having at least one son & & & -0.13 & 0.88 & -0.11 & 0.90 \\
\hline
\end{tabular}


Functional social support:

Receiving support:

Financial support (baseline)

Financial support (ending year)

0.16

$-0.04$

1.17

0.97

$-0.0$

1.24
0.99

0.99

Instrumental support (ending year)

0.14
-0.19

Emotional support (baseline)

Number of support (baseline)

$-0.13$

1.15

0.83

$0.87 *$

$-0.02$

0.97

0.16

$-0.35$

Number of support (ending year)

0.02

$-0.19$

1.02

$0.8_{3}$

Financial support (ending year)

Instrumental support (baseline)

0.19

$-0.27$

Emotional support (baseline)

0.24

Emotional support (ending year)

Number of support (baseline)

Number of support (ending year)

0.02
-0.06

o.06

1.21

0.76

1.27

1.02

0.94

1.06

0.23

0.29

0.70

1.25

1.33

$0.15 \quad 1.16$

$-0.83 \quad 0.44^{*}$

$-0.15 \quad 0.86$

Statistically significant interaction term:

Filial attitudes $\times$ widowhood

Filial attitudes $\times$ receiving emotional support

0.22

1.06

$0.02 \quad 1.02$

$\begin{array}{ll}0.07 & 1.07\end{array}$

$0.21 \quad 1.23$

$0.18 \quad 1.74$

$0.24 \quad 1.27$

$0.55 \quad 1.74$

$\begin{array}{ll}0.07 & 0.94\end{array}$

$\begin{array}{ll}0.11 & 0.90\end{array}$

Notes: $\mathrm{N}=3,882$. ADL: activity of daily living. PGC: Philadelphia Geriatric Center. POR: proportional odds ratio.

Significance levels: $\uparrow p<0.1, * p<0.05, * * p<0.01, * * * p<0.001$ 
widowhood tended to be negatively associated with parents' psychological wellbeing. The result suggested that parents' status as widowed increased by 37 per cent the relative likelihood of reporting a lower level of morale. Another structural family support variable that showed its relative importance was parent's co-residence with a child, which presented a tendency of positive influence on parent's psychological wellbeing. The living arrangement of co-residence in itself entails multiple issues (e.g. quality of family relationships); therefore, we are not in the position of imposing any definite direct relationship between the two. However, it is noteworthy that parents living with children in Japan tended to show a relatively high level of morale.

Turning to the functional dimension of social support, two functional support variables were found to be significantly associated with parental morale: receiving emotional support from at least one child and baseline amount of support received from children. The analysis showed that, controlling the patterns of social support at the initial stage of the study interval, receiving emotional support from a child was negatively associated with parent's morale $(\mathrm{POR}=0.44)$. Additionally, the number of support items received by parents from children at the initial stage of the study interval was negatively associated with parent's morale two or three years later.

In our final model, we constructed 12 interaction terms where each of the 12 measures of structural and functional family support was interacted with the variable of parent's filial attitudes, respectively. Of these 12 interaction terms, the interaction between parents' normative attitudes and widowhood was significant. The positive interaction term indicated that the negative association between widowhood and a parent's morale tended to be lessened if the parent expressed more affirmative attitudes toward the traditional norm of filial responsibilities. Although it was not at the conventional level of statistical significance, we also found that the interaction between parents' normative attitudes and receiving emotional support was relatively important $(p=0.07)$. The analysis indicated that parents who embraced the traditional norm of filial responsibilities tended to have a higher morale than less traditional parents when they received emotional support from their children. We note that statistical tools to test the overall model fitness of logistic analyses in multi-stage sampling designs are still in progress (Archer and Lemeshow 2006). Implementation of the currently available testing methods proposed by Archer and Lemeshow (2006) provided us with limited support to our overall model design, suggesting further sophistication of the model needs to be carefully considered in the future. 


\section{Discussion}

Our results revealed that the structural and functional dimensions of family support examined had a limited association with parents' morale. In particular, among the different ways to measure availability of social support, whether or not an older individual had been widowed was one of the few factors that appeared to be relatively important for older parent's psychological wellbeing. This result implies a potential risk widowed parents may be exposed to psychologically. On the other hand, most of the variables related to the availability of adult children for support were not identified as relevant to parents' morale. As for functional aspects of family support, we examined both quantity and different types of support older parents provided and received from their children. While the amount of support provided by parents to children did not appear to be related to their morale, receiving a relatively large amount of support from children at the beginning of the study interval was significantly associated with a lower level of morale in the end of the two- or three-year study interval. This agrees with a number of studies in Western societies that have suggested that excessive amounts of support to parents may have a negative influence on older adults' psychological wellbeing (Davey and Eggebean 1998; Silverstein, Chen and Heller 1996).

Among the different functions of social support we examined, our analysis showed that receiving emotional support from a child tended to be related to lower morale in older parents. On the other hand, receiving or providing financial or instrumental support did not show a significant influence. Whereas financial and instrumental support involve exchange of tangible materials, receiving emotional support means older parents spend time with children, opening up and talking about worries, asking for advice and seeking comfort. In this sense, older parents may feel that receiving emotional support is harder to deal with when compared to other types of support that do not require similar personal disclosures. Alternatively, as argued elsewhere with similar issues (Seeman, Bruce and McAvay 1996), lower levels of morale may have triggered older parents' tendency to rely on children for emotional support. Because it is unclear whether low morale precedes the need for emotional support, or is a result of it, the exact order of each phenomenon should be determined in order to study further these theories. Nevertheless, the result highlights an interesting difference between emotional support and the other two types of support examined in this study.

Different operational and statistical models make direct comparisons of results quite challenging. We note, however, that our finding that receiving emotional support is linked to negative psychological consequences 
contradicts several cross-sectional studies conducted in the past. Those studies reported receiving emotional support had a positive effect on an older adult's psychological state (Chen and Silverstein 2000; Tiedt 2010). This discrepancy may be due to the fact that our longitudinal analysis captured data shortly after individuals began receiving emotional support because we controlled the support behaviours reported at the initial time of the two- or three-year study interval. While cross-sectional studies may consider on-going emotional support and crisis-based emotional consultation, our longitudinal analysis likely reported more of the latter. Depending on the timing, nature and quality of emotional support, its impact on an older adult's psychological wellbeing could be substantially different. In order to tease out factors that may affect older adult's psychological wellbeing differently depending on external circumstances, more detailed information about the support parents and children provide and receive needs to be incorporated.

Against our expectation based on findings in Western societies (e.g. Thomas 2010), provision of types of support did not have a significant influence on older parents' morale. This result suggests that there may be a cultural difference in the ways in which older parents experience and perceive their providing support to adult children. Further analysis is needed to examine the conditions in which provision of support to children is likely to occur in Japan compared to other societies.

This study also examined how older parents' attitudes toward the traditional norm of filial responsibilities modify the relationship between family support and their morale level. Our analysis identified a significant interaction between widowhood and older parents' filial attitudes. Controlling marital status measured both at the beginning and at the end of the study interval, when parents had a relatively positive attitude toward children's filial responsibilities, we observed a weaker negative association between their widowhood status and their morale.

The relatively important connection we observed between parents' attitudes and receiving emotional support also suggests that a belief in filial responsibilities tends to mitigate the negative association between older parents relying on their children for advice and comfort and their morale level. The other side of this argument suggests that parents who embrace the norm of independence may be particularly vulnerable to psychological damage when they receive such support from their children.

We note that what we measured in this study was the parents' normative attitudes, which presumably reflect what parents consider to be ideal. The study did not ask what each participant personally believed in or expected from his or her own children. Normative attitudes are, however, intricately intertwined with one's personal experience with families (Logan and 
Bian 1999; Takagi and Silverstein 2006). In other words, what parents perceive as ideal may reflect what they expect from their children, or what they have experienced with their own children. Wethington and Kessler (1986) discussed how a person's perception about the potential availability of support has a strong stress-buffering effect. Although our inquiry into filial attitudes did not measure whether people perceived that actual support was available, it is possible that the normative beliefs measured in this study may partially represent participants' personal perception and expectation about their own children. Regardless whether it is strictly normative or partially personal, however, a parent's belief in filial responsibilities seems to have some moderating effect on parents' morale in certain circumstances.

Besides the discussion of structural and functional support, we also note that overall, a relatively small portion of the study participants reported they both received and provided support. This is notable because the sample had a relatively high rate of co-residence with children compared to what is normally seen in Western societies. Exchange of support tends to be especially frequent when parents and children live in the same house (Pezzin and Schone 1997). Our preliminary analysis indeed indicated that there was a significant discrepancy in amount of reported intergenerational support between parents who co-resided with a child and parents who did not (results available upon request). The overall low frequency of support exchange between parents and children suggest that there is a low frequency of support for parents who do not live with children. This reflects the findings of a previous cross-national study on intergenerational contact, which reported Japanese older adults being at one of the lowest levels of social interaction, especially with non-coresiding children (Cabinet Office 2005). The implication is that the delivery and exchange of support between older parents and adult children may have become a more challenging task in Japan particularly for parents and children who maintain separate households. The result demands more thorough analysis of social support in the future that focuses on the needs of a growing number of Japanese parents who do not live with children.

It is also noteworthy that two socio-demographic conditions - the older adults' relatively high educational level and better physical health condition - were consistently identified as strong indicators of psychological wellbeing. While individuals with a higher level of education tended to maintain better morale, parents' household income did not significantly predict their morale. Previous studies have found that older adults with a higher level of education are more likely to express negative attitudes toward the traditional family norm, while no similar effect was found with respect to income level (Takagi and Silverstein 2006). This suggests that for older adults in Japan, educational background and income level may 
be distinctively different when considered as determinants of their psychological wellbeing. As the vast majority of literature reports, having a physical limitation with respect to basic living activities tends to result in a negative psychological consequence in older parents. The finding in our study provided another reminder that older adults with a physical disability, as well as their family members, are in an especially challenging situation with regard to maintaining their psychological wellbeing.

In order to properly understand the results and findings of this study, it is necessary to recognise several limitations. First, this longitudinal study was not able to incorporate information about the adult children who provided, reciprocated or received support from their older parents. This was because the surveys did not longitudinally identify the children reported in each year, which hindered us from linking their information across waves. Many studies suggest that the quality and function of the relationships parents and children develop in later life vary significantly. For example, gender of parents and children can play a role in these differences (e.g. Cong and Silverstein 2008; Lee, Spitze and Logan 2003; Rossi 1993).

Additionally, this survey did not have information about the older parents' subjective rating of the support they exchanged with their children, or about their perception regarding the quality of the relationships they had with their spouse and children. A number of studies on social support mention parents' perceptions regarding the quality of relationships with their children and the support they exchange as important determinants of their psychological wellbeing (e.g. Chen and Silverstein 2000; Phillips et al. 2008). As noted earlier, our measurement of parents' normative attitudes toward filial responsibilities may partially reflect the perceptions of parents.

Finally, it is also important to note that while our pooled ordered logit model strengthens the discussion of association between family support and parent's morale, the model is still limited. Because some key variables (e.g. filial attitudes) were not available in all four waves, we could not implement models that may be more suited for longitudinal analyses (e.g. fixed-effects model).

Despite these limitations, we contend that this study makes a significant contribution to extending our understanding of the ways in which family support promotes or jeopardises older parents' psychological wellbeing in Japan. In contemporary Japanese society where the collective norm of filial piety coexists with the emerging notion of individualism in later years, our analyses showed that widowed older parents had a lower level of psychological wellbeing. Furthermore, this trend was especially salient for parents who expressed less faith in filial responsibilities for ageing parents. 
Our results also showed that older parents who have emotional reliance on children tend to express a relatively low level of morale. At the same time, however, parents who believe in children's obligation for parents are likely to show some leverage of their psychological state when compared to parents with less traditional attitudes. These findings suggest that parents' normative belief and attitudes potentially play a critical role in determining the ways in which family support influences their psychological wellbeing. This implies that there is significant diversity within the older population in Japan, where the meaning and actual benefit of family support for older adults differ among parents who express varying degrees of agreement with the traditional family norm. In the complex social atmosphere where independence from children and traditional filial obligations coexist, the impact of family support on older parent's morale may not have a universal trend but rather may manifest in diverse manners among older parents.

\section{Acknowledgements}

This study was partially supported by a grant, Academic Frontier Project for Private Universities by MEXT (2006-2010) to Nihon University, and by a Grant-in-Aid for Scientific Research from the Japan Society for the Promotion of Science, 23330085. We also appreciate the thoughtful comments and suggestions provided by the anonymous reviewers.

\section{References}

Antonucci, T. C. and Akiyama, H. 1996. Convoys of social relations: family and friendships within a life span context. In Blieszner, R. and Bedford, V. H. (eds), Aging and the Family: Theory and Research. Praeger, Westport, Connecticut, $353-71$.

Archer, K. J. and Lemeshow, S. 2006. Goodness-of-fit test for a logistic regression model fitted using survey sample data. The State Journal, 6, 1, 97-105. Available online at http://www.stata-journal.com/sjpdf.html?articlenum=stoog9 [Accessed March 2012].

Brown, J., Winchester, Liang, J., Krause, N., Akiyama, H., Sugisawa, H. and Fukaya, T. 2002. Transitions in living arrangements among elders in Japan: does health make a difference? Journals of Gerontology: Social Sciences, 57B, 4, S2O9-20.

Cabinet Office 2005. Sixth Cross-national Comparative Survey: Lives Among Older Adults. Cabinet Office, Tokyo. Available online at http://www8.cao.go.jp/kourei/ishiki/ h17_kiso/index2.html [Accessed September 2011].

Cabinet Office 2011. Korei-Shakai Hakusho [Annual Report on the Aging Society $\left.20 I_{I}\right]$. Tokyo, Japan. Available online at http://www8.cao.go.jp/kourei/ whitepaper/w-2011/zenbun/23pdf_index.html [Accessed August 2011]. (In Japanese)

Cantor, M. H. 1979. Neighbors and friends. Research on Aging, 1, 4, 434-63. 


\section{Emiko Takagi and Yasuhiko Saito}

Chen, X. and Silverstein, M. 2000. Intergenerational social support and the psychological well-being of older parents in China. Research on Aging, 22, 1, 43-65.

Cheng, S.-T. and Chan, A. C. M. 20o6. Filial piety and psychological well-being in well older Chinese. Journals of Gerontology: Psychological Sciences and Social Sciences, 61B, 5, P262-9.

Cong, Z. and Silverstein, M. 2008. Intergenerational support and depression among elders in rural China: do daughters-in-law matter? Journal of Marriage and Family, 7o, $3,599-612$.

Davey, A. and Eggebean, D.J. 1998. Patterns of intergenerational exchange and mental health. Journals of Gerontology: Psychological Sciences, 53B, 2, 86-95.

Eggebeen, D. J. 1992. Family structure and intergenerational exchanges. Research on Aging, 14, 4, 427-47.

Elwert, F. and Christakis, N. A. 2006. Widowhood and race. American Sociological Review, 71, 1, 16-41.

Hayashi, F. 1995. Is the Japanese extended family altruistically linked? A test based on engel curves. The Journal of Political Economy, 103, 3, 661-74.

Kim, H. K., Hitsuru, M., Kai, I. and Lee, S.-K. 200o. Social support exchange and quality of life among the Korean elderly. Journal of Cross-cultural Gerontology, $\mathbf{1 5}$, $4,331-47$.

Kim, I. K. and Kim, C. 2003. Patterns of family support and the quality of life of the elderly. Social Indicators Research, 62/63, 437-54.

Koyano, W. 1994. The social support system of the Japanese elderly. Journal of Crosscultural Gerontology, 9, 3, 323-33.

Koyano, W. 1996. Filial piety and intergenerational solidarity in Japan. Australian Journal on Ageing, 15, 2, 51-6.

Kumagai, F. 1996. Unmasking Japan Today: The Impact of Traditional Value on Modern Japanese Society. Praeger, Westport, Connecticut.

Lawton, M. P. 1975. The Philadelphia Geriatric Center Morale Scale: a revision. Journal of Gerontology, 3o, 1, 85-9.

Lee, E., Spitze, G. and Logan, J. R. 2003. Social support to parents-in-law: the interplay of gender and kin hierarchies. Journal of Marriage and the Family, $\mathbf{6}_{5}, 2$, $396-403$.

Lee, G. R. and DeMaris, A. 2007. Widowhood, gender, and depression: a longitudinal analysis. Research on Aging, 29, 1, 56-72.

Lee, G. R., Netzer, J. K. and Coward, R. T. 1995. Depression among older parents: the role of intergenerational exchange. Journal of Marriage and the Family, 57, $3,823-33$.

Li, S., Song, L. and Feldman, M. W. 20og. Intergenerational support and subjective health of older people in rural China: a gender-based longitudinal study. Australasian Journal on Ageing, 28, 2, 81-6.

Liang, J., Asano, H., Bollen, K. A. and Kahana, E. F. 1987. Cross-cultural comparability of the Philadelphia Geriatric Center Morale Scale: an American-Japanese comparison. Journal of Gerontology, 42, 1, 37-43.

Logan, J. R. and Bian, F. 1999. Family values and coresidence with married children in urban China. Social Forces, 77, 4, $1253-82$.

Maeda, D. and Ishikawa, H. 2000. Ageing in Japan: retirement, daily lives, pensions and social security. In Phillips, D. R. (ed.), Aging in the Asia-Pacific Region: Issues, Policies, and Future Trends. Routledge, New York, 1 13-32.

Muramatsu, N. and Akiyama, H. 2011 . Super-aging society preparing for the future. The Gerontologist, 51, 4, 425-32.

Ogawa, N., Mason, A., Matshukura, M. R. and Nemoto, K. 2007. Population aging and health care spending in Japan: public- and private-sector 
responses. In Clark, R., Ogawa, N. and Mason, A. (eds), Population Aging, Intergenerational Transfers and Macroeconomy. Edward Elgar, Northampton, Massachusetts, 192-226.

Öztop, H., Şener, A., Güven, Ş. and Doğan, N. 20og. Influences of intergenerational support on life satisfaction of the elderly: a Turkish sample. International Journal of Social Behavior EO Personality, 37, 7, 957-69.

Palmore, E. B. 1975. What can the USA learn from Japan about aging? The Gerontologist, 15, 1, 64-7.

Penning, M.J. 1990. Receipt of assistance by elderly people: hierarchical selection and task specificity. The Gerontologist, 3o, 2, 220-7.

Pezzin, L. E. and Schone, B. S. 1997. The allocation of resources in intergenerational households: adult children and their elderly parents. The American Economic Review, 87, 2, 460-4.

Phillips, D., Siu, O., Yeh, A. and Cheng, K. 2008. Informal social support and older persons' psychological well-being in Hong Kong. Journal of Cross-cultural Gerontology, 23, $1,39-55$.

Roberts, E. R., Richards, L. N. and Bengtson, V.L. 1991. Intergenerational solidarity in families: untangling the ties that bind. Marriage and Family Review, 16, $1,11-46$.

Rossi, A.S. 1993. Intergenerational relations: gender, norms, and behavior. In Bengtson, V.L. and Achenbaum, A.W. (eds), The Changing Contract Across Generations. Walter de Guyer, New York, 191-211.

Seeman, T. E., Bruce, M. L. and McAvay, G.J. 1996. Social network characteristics and onset of ADL disability: MacArthur studies of successful aging. Journals of Gerontology: Social Sciences, 51B, 4, S191-200.

Silverstein, M. and Bengtson, V.L. 1997. Intergenerational solidarity and the structure of adult child-parent relationships in American families. American Journal of Sociology, 103, 2, 429-6o.

Silverstein, M., Chen, X. and Heller, K. 1996. Too much of a good thing? Intergenerational social support and the psychological well-being of older parents. Journal of Marriage and the Family, 58, 4, 970-82.

Silverstein, M., Cong, Z. and Li, S. 2006. Intergenerational transfers and living arrangements of older people in rural China: consequences for psychological well-being. Journals of Gerontology: Psychological Sciences and Social Sciences, 61 B, 5, $\mathrm{S}_{25} 6-66$.

Takagi, E. and Silverstein, M. 2011. Purchasing piety? Coresidence of married children with their older parents in Japan. Demography, 48, 4, 1559-79.

Takagi, E. and Silverstein, M. 2006. Intergenerational coresidence of the Japanese elderly: are cultural norms proactive or reactive? Research on Aging, 28, 4, 473-92.

Thomas, P. A. 2010. Is it better to give or to receive? Social support and the well-being of older adults. Journals of Gerontology: Psychological Sciences and Social Sciences, $\mathbf{6}_{\mathbf{5}} \mathbf{B}, 3$, $35^{1-7}$.

Tiedt, A. D. 2010. The gender gap in depressive symptoms among Japanese elders: evaluating social support and health as mediating factors. Journal of Cross-cultural Gerontology, 25, 3, 239-5 6 .

Tsuya, N. O. and Martin, L. G. 1992. Living arrangements of elderly Japanese and attitudes toward inheritance. Journals of Gerontology: Social Sciences, 47, 2, $\mathrm{S}_{45}-54$.

Umberson, D., Wortman, C. B. and Kessler, R. C. 1992. Widowhood and depression: explaining long-term gender differences in vulnerability. Journal of Health E Social Behavior, 33, 1, 10-24.

USC/UCLA Center on Biodemography and Population Health 2004. Nihon University Japanese Longitudinal Study of Aging, Tokyo, Japan. Available online 
1076 Emiko Takagi and Yasuhiko Saito

at http://www.usc.edu/dept/gero/CBPH/nujlsoa/index.htm [Accessed August $2011]$.

Wethington, E. and Kessler, R. C. 1986. Perceived support, received support, and adjustment to stressful life events. Journal of Health $\mathcal{E}$ Social Behavior, 27, 1, 78-89.

Accepted 23 April 2012 ; first published online I 8 June 2012

Address for correspondence:

Emiko Takagi, Department of Health Science, Towson University, 8 ooo York Road, Towson, MD $2125^{2-0001, ~ U S A . ~}$

E-mail: etakagi@towson.edu 